\title{
Epigenetics and phenotypic variability: some interesting insights from birds
}

\author{
Laure Frésard ${ }^{1,2 \dagger}$, Mireille Morisson ${ }^{1,2 \dagger}$, Jean-Michel Brun ${ }^{3}$, Anne Collin ${ }^{4}$, Bertrand Pain ${ }^{5}$, Francis Minvielle ${ }^{6,7}$ \\ and Frédérique Pitel ${ }^{1,2^{*}}$
}

\begin{abstract}
Little is known about epigenetic mechanisms in birds with the exception of the phenomenon of dosage compensation of sex chromosomes, although such mechanisms could be involved in the phenotypic variability of birds, as in several livestock species. This paper reviews the literature on epigenetic mechanisms that could contribute significantly to trait variability in birds, and compares the results to the existing knowledge of epigenetic mechanisms in mammals. The main issues addressed in this paper are: (1) Does genomic imprinting exist in birds? (2) How does the embryonic environment influence the adult phenotype in avian species? (3) Does the embryonic environment have an impact on phenotypic variability across several successive generations? The potential for epigenetic studies to improve the performance of individual animals through the implementation of limited changes in breeding conditions or the addition of new parameters in selection models is still an open question.
\end{abstract}

\section{Review}

Most economically relevant traits in animal production exhibit continuous phenotypic variations due to polygenic and environmental factors. Whereas many quantitative trait loci (QTL) have been identified for agronomic traits, in most cases, the underlying genes remain largely unknown. Genome-wide association studies have shown that, except for rare monogenic traits, the variability of complex traits is only partially explained by genetic variation [1]. Possible explanations include epistatic effects, structural variations, and insufficient detection power due to lack of individuals or markers [1,2]. Both epidemiological studies in humans and genetic studies in animals have revealed that, in addition to the DNA sequence, epigenetic marks may be transmitted across generations and influence the phenotype of offspring [3]. There are many discussions in the literature on what the term "epigenetics" refers to and this leads to numerous definitions [3-11]. While some definitions restrict epigenetics to modifications of the phenotype

\footnotetext{
* Correspondence: frederique.pitel@toulouse.inra.fr

${ }^{\dagger}$ Equal contributors

'INRA, UMR444, Laboratoire de Génétique Cellulaire, Castanet-Tolosan F-31326, France

ENVT, UMR444, Laboratoire de Génétique Cellulaire, Toulouse, F-31076, France

Full list of author information is available at the end of the article
}

without changes of the DNA sequence that are transmitted to the next generations [4], other broader definitions include any form of information storage that maintains the DNA sequence intact, as described by Bird: "the structural adaptation of chromosomal regions so as to register, signal or perpetuate altered activity states" [7]. The former definitions link the term "epigenetic" to inheritance and the latter also refer to any phenomenon that leads to phenotypic plasticity. These two visions share a common feature i.e. the molecular mechanisms involved. The epigenetic machinery encompasses chromatin folding and its attachment to the nuclear matrix, packaging of DNA around nucleosomes, covalent modifications of histone tails, DNA methylation, and regulatory non coding RNA (such as miRNA, snoRNA, lncRNA). Epigenetic marks have been shown to actively contribute to the determination of patterns of gene silencing or active transcription, and to participate in the lineage and tissue-specific expression of genes [12-14]. Epigenetic marks are heritable from cell to cell through lineage development, and when acquired in early life, they can have an impact on the adult phenotype. They can also have an impact on the phenotypes of subsequent generations through multigenerational effects that occur either via epigenetic changes acquired during embryonic development, or through the inheritance of

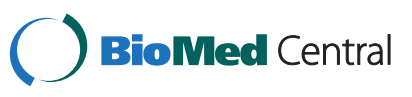


epigenetic marks via the gametes [3,15]. In this review, we retain the definition given by Feil and Fraga [14]: "Epigenetics is the study of mitotically and/or meiotically heritable changes in gene function that cannot be explained by changes in DNA sequence".

Understanding the epigenetic regulation of gene expression due to environmental factors should provide important new insights into animal breeding, since the same genetic information may be used differently by individuals grown in different environments. However, epigenetic regulation of gene expression is not always environment-dependent as for parental imprinting in which parent-of-origin-specific expression of a subset of genes is regulated by epigenetic mechanisms. Examples of such loci have been documented in livestock species i.e. the locus responsible for the callipyge phenotype in sheep [16] and the locus that controls IGF2 expression in pigs [17].

The first agricultural species to be fully sequenced was the chicken, however, to date, there are few studies on the relation between epigenetic processes and economically important phenotypes in birds. This review focuses on how epigenetic phenomena can have an impact on the adult phenotype of farmed birds.

The importance of sex-linked genes that account for some of the phenotypic variability has been shown in the chicken [18] and X inactivation that involves epigenetic mechanisms is well known in mammals $[19,20]$. In birds, only partial dosage compensation between the hetero(ZW, female) and homogametic (ZZ, male) sexes has been described [21,22] and this was previously known as "lack of global dosage compensation" [23]. A region of hypermethylation (MHM for Male Hypermethylated Region, [24]) is associated with dosage-compensation of several genes in the male chicken [25-27], but not in zebra finch [21]. Many questions about the mechanisms of regional dosage-compensation still remain [26,28]. Since this topic has already been extensively reviewed, we refer the reader to the literature, including the references given above. By contrast, little is known about the mechanisms of genomic imprinting, if present, or developmental programming in birds although they may play a role in phenotypic variability as shown in mammalian farm animals. Similarly, epigenetic information that can be transmitted through several generations could have a significant impact on animal selection.

This review addresses the following questions: (1) Are there molecular mechanisms leading to genomic imprinting in birds? (2) While the influence of fetal environment on adult phenotypes is largely documented in mammals, what are the developmental and metabolic phenotypes due to specific environmental cues in birds? (3) Are there examples indicating that embryonic environment has multigenerational effects in birds?

\section{Genomic imprinting}

To discuss the state of knowledge regarding genomic imprinting in birds, the mechanisms known in mammals will be compared to the information available in avian species. To date, among vertebrates, genomic imprinting has been described only in eutherian mammals and marsupials. Parental imprinting (Figure 1), a process that leads to the differential expression of alleles depending on their parental origin (see [29] for a review), is stage- and tissuespecific [30,31]. The major theory explaining genomic imprinting is the parental conflict hypothesis [32,33], which states that the genes responsible for controlling the supply of maternal resources have a parentally biased expression, with the maternal genome tending to restrain resource allocations to preserve the mother and future progeny, while the paternal genome tends to facilitate this allocation to produce stronger offspring. Based on this theory, it can be assumed that genomic imprinting is restricted to organisms in which the maternal resources affect directly the embryonic genes, and thus its existence would be unlikely in oviparous animals [34].

In avian species, important reciprocal effects involving asymmetry in the contributions of the sire and dam to the offspring phenotype have been described for some traits. They explain 15 to $20 \%$ of the phenotypic variability in broiler body weight and egg viability in layers, and up to $47 \%$ in turkey egg production, and they have been extensively used to improve production in layers by

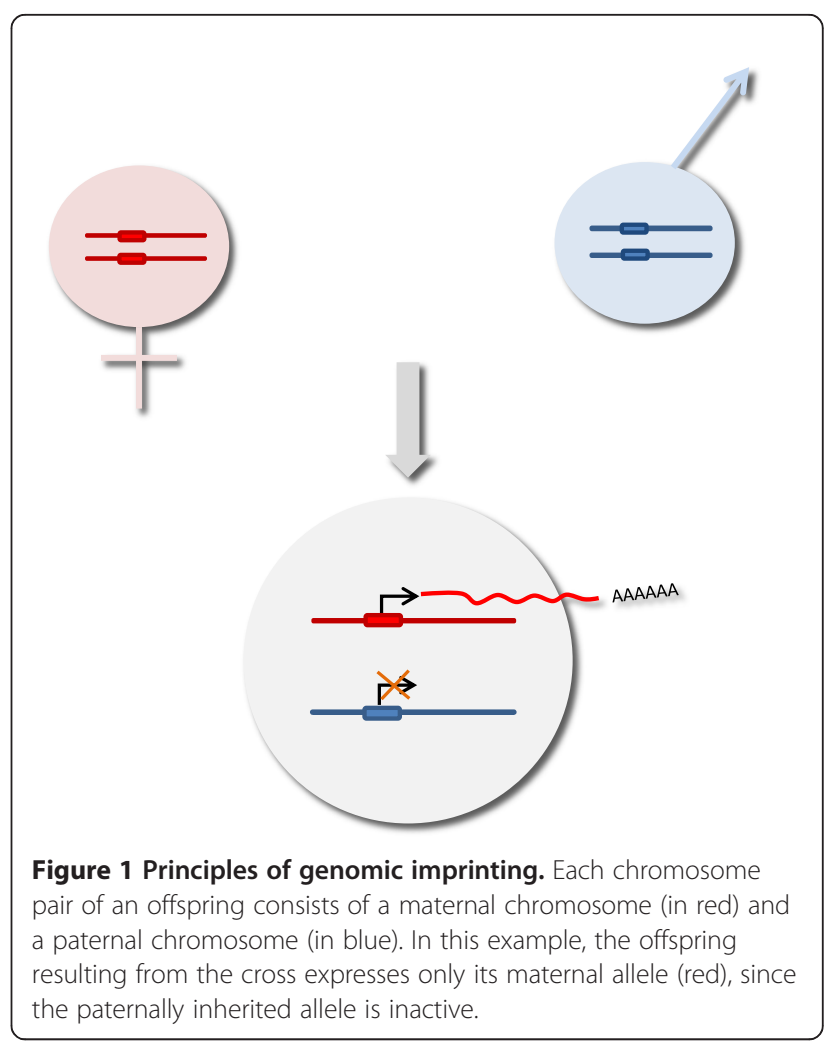


designing optimized mating schemes [35]. These effects are mainly due to sex-linked genes, underlying the importance of chromosome $\mathrm{Z}$ in epigenetic effects, direct maternal effects ("larger females produce larger eggs") or mitochondrial DNA transmission [18]. However, this does not exclude the hypothesis that some of these effects may originate from parent-of-origin preferential allelic expression [36,37], and efforts to identify the genes involved in quantitative traits are increasingly taking epistatic and epigenetic effects into account. In the chicken and quail, many parent-of-origin QTL have been detected for traits linked with production [37-41], immune responses [42] and behavior [43]. However, such studies can detect spurious QTL due to linkage disequilibrium or bias generated by the experimental design $[44,45]$. A study reported by Rowe et al. [37] was specifically designed to avoid these biases i.e. it included a sufficient number of sires and dams to ensure segregation and a sufficient number of offspring to detect QTL with roughly equal allele frequencies in sires and dams for both QTL and molecular markers, and it fitted the common maternal environment in the linear model. Interestingly, this work confirmed the presence of a parent-of-origin QTL on chicken chromosome 1, in a region corresponding to orthologous imprinted regions in the human and mouse genomes. These results confirm the importance of studying genomic imprinting in birds.

Several studies have clearly demonstrated that some genes are paternally or maternally expressed during embryonic development in mammals [46-48]. Until recently, less than 200 imprinted genes were described (http://igc. otago.ac.nz/home.html) but a transcriptome sequencing approach reported in 2010 [49] uncovered parent-of-origin allelic effects for more than 1300 loci in the mouse. However, this large number is the subject of much debate $[50,51]$, and to date, no consensus on the number of imprinted genes in mammals has been reached.

Some genes, known to be imprinted in mammals, have been examined in non eutherian vertebrates, in particular oviparous species [52], including birds, viviparous marsupials [53], and monotremes [54,55]. The IGF2 gene, which has long been known to be paternally expressed in the mouse and man [56], has also been analyzed in the chicken. A preliminary report suggested that its expression is probably monoallelic [57], but later studies agreed that it is in fact biallelic [52,58-61]. In this case, analyses of different chicken tissues and at different growth stages led to divergent conclusions, emphasizing the importance of tissue sampling and time scaling in imprinting studies. The orthologs of other genes known to be imprinted in mammals, such as ASCL2/MASH2 (a fully imprinted region in mammals), M6PR/IGF2R, DLK1 and UBE3A were found to be biallelically expressed in the chicken [61-63]. Moreover, the H19 imprinting center identified in mammals and controlling an imprinted cluster that includes IGF2, appears to be absent in the chicken [61].

However, such studies are limited to few genes (less than $5 \%$ of the genes known to be imprinted in the mouse) in different chicken embryonic tissues at different developmental stages. They are not sufficiently exhaustive to conclude that imprinting does not exist in birds, especially since different sets of genes might be imprinted in mammals versus birds.

Several studies have examined imprinted-related molecules and phenomena to better understand genomic imprinting in mammals. If applied to the chicken, this approach may also help test for the existence of genomic imprinting in birds.

One feature of imprinted regions in mammals is the asynchronous replication of parental alleles [64]. Interestingly, replication of the chicken orthologs of some imprinted genes is asynchronous [65], even when they are biallelically expressed. It is hypothesized that mammalian imprinted gene clusters originate from an ancestor common to all vertebrates and that they evolved from preimprinted to imprinted regions [66]. Since the orthologous mammalian imprinted genes are biallelically expressed in the chicken, it is impossible to strictly link the asynchronous replication to imprinting in birds.

Another feature of mammalian imprinting is its association with several molecular signatures. As recently reviewed, these signatures need to differentiate paternal and maternal inherited chromosomes in order to influence transcription, and to be transmitted through generations [67]. Changes in DNA methylation patterns represent an ideal mechanism to generate such signatures or epigenetic marks. DNA methylation is involved in the regulation of gene expression, and specific methylation patterns can be inherited across generations in mammals. The enzymes that control DNA methylation, such as DNA methyltransferases (DNMT), are crucial for embryonic survival in the mouse (recently reviewed in $[68,69]$ ). DNMT include proteins that act in the maintenance of DNA methylation, such as DNMT1, and proteins that are involved in de novo DNA methylation, either by directly interacting with DNA (DNMT3A and DNMT3B) or indirectly as supporting factors (DNMT3L) [70-74]. The respective roles of DNMT in genomic imprinting have been brought to light mainly through loss-of-function (knockdown or knockout) experiments [75,76]. Identification of methylation-related DNMT in chickens would stimulate the search for allele-specific expression in oviparous animals. DNMT1, DNMT3A and DNMT3B cDNA have been cloned in the chicken, and their encoded proteins have been shown to share $50-80 \%$ amino acid identities with the corresponding mouse orthologs [77,78]. However, $D N M T 3 L$, a gene that encodes a protein essential for the establishment of imprinted marks in the mouse [79] has 
not been detected in birds [77], which may explain why some genes imprinted in mammals are not imprinted in the chicken.

Another approach for investigating genomic imprinting is to explore the chicken genome for differentially methylated regions (DMR) that are involved in the differential methylation of maternal and paternal chromosomal DNA in mammalian imprinting. A genome-wide methylome map of chicken muscle and liver tissues was completed recently [80], and the authors did not identify any DMR associated with genes known to be imprinted in mammals. However, this search was performed for only a few genes in two tissues, and thus it is difficult to draw conclusions on the existence of imprinted genes across the chicken genome.

Although methylation patterns play a major role in the process of allele silencing, other mechanisms (e.g., histone modifications or non-coding RNA) are also known to be involved at several stages [81-84]. Among the numerous studies on this subject, two deserve particular attention. First, a study on mouse placenta has shown that genetic ablation of DNA methylation does not suppress imprinting of paternally repressed genes located in the distal region of mouse chromosome 7 [85] but that histone methylation seems sufficient to confer a silenced status to the paternal alleles of the relevant genes. The authors suggest the existence of an older imprinting mechanism that is limited to extra-embryonic tissues and that involves histone modification. In the second study, the authors examined the mouse Gnas cluster (located on mouse chromosome 2, containing a gene coding for stimulatory G-protein alpha subunit, giving rise to alternatively spliced isoforms that show maternal-, paternal- and biallelic expression as well as a non-coding antisense transcript [86]). They demonstrated that Nespas, a non-coding RNA, could silence Nesp by a mechanism independent of a DNA methylation mark [87]. Again, a DNAmethylation-independent role of chromatin marks in gene silencing was highlighted. These two studies show that imprinting mechanisms other than DNA methylation exist, and it is interesting to note that such mechanisms have not yet been investigated in birds.

Genome-wide approaches [49,88,89] and developments such as next-generation sequencing have recently opened up new perspectives for the investigation of imprinting mechanisms, including the possibility of identifying unknown mechanisms and gaining insight into new interactions or alternative processes. As suggested in a recent review [90], it is essential to explore other vertebrate lineages for epigenetic marks and allele-specific expression.

\section{Environmental epigenomics}

The environment can influence developmental plasticity and thus phenotypes in a wide variety of animals, from insects to man [14]. Environmental epigenomics refers to the study of how environmental exposures (e.g., toxins, stress or maternal nutrition) during early development influence gene regulation through epigenetic mechanisms (e.g., DNA methylation or histone modifications) that, in turn, influence the adult phenotype [14,91-93]. As described below, the environment may have a much broader impact on the adult phenotype when the marks occur early during development.

\section{Post-hatch environmental influences}

Several studies on DNA and histone methylation levels in chicks subjected to heat stimulation demonstrated that epigenetic marks vary with the environmental conditions experienced during the post-hatch period [94-97]. They showed that the expression of BDNF (brain-derived neurotrophic factor), which is a key regulator of thermotolerance acquisition in the chick hypothalamus, differs between control birds and animals acclimated to heat early in their post-hatch life. Furthermore, alterations were observed in the methylation level of CpG sites in the promoter of the BDNF gene. It was also shown that modifications of histone $\mathrm{H} 3$ lysine 9 (H3K9) and methylation of histone $\mathrm{H} 3$ lysine residue 27 (H3K27) in the promoter of BDNF occur in the hypothalamus during thermotolerance acquisition on day 3 post-hatch.

Epigenetic modifications are involved in the immune mechanisms underlying chicken susceptibility to Salmonella enteritidis [98] or Marek disease [99,100] and include changes in the DNA methylation pattern of host defense genes. Indeed, the Marek disease virus (MDV) can induce changes in the expression levels of all three DNMT genes (DNMT1, DNMT3A, and DNMT3B). Various histone profiles and gene promoters were identified as being differentially modified and methylated in MDVsensitive and -resistant chicken strains, indicating that epigenetic mechanisms may participate in the modulation of the resistance and/or susceptibility to specific poultry diseases $[99,100]$.

Other environmental changes are known to affect the adult phenotype, but to date, no molecular evidence of epigenetic phenomena is available. For instance, phosphorus- or calcium-restricted diets during the early growing period trigger a compensatory adaptation of the chicken [101], possibly mediated by epigenetic mechanisms [102]. Although little is known about the underlying molecular mechanisms in birds, it seems that feed stress may alter gene transcription at least partly via epigenetic mechanisms. For example, Xu et al. [103] reported that 3day-old chicks subjected to a 24-hour fasting underwent histone $\mathrm{H} 3$ methylation modifications in the preoptic anterior hypothalamus, which is the center of body temperature and food intake control. 


\section{Influence of the environment during development}

In addition to post-hatch environmental factors, changes applied directly to the egg or the resources contained in the egg (e.g., nutrients, hormones, carotenoids, vitamins or RNA transcripts) can have an impact on newborn fitness and later on the adult phenotype $[104,105]$. Thus, these environmental effects on development are either directly applied to the embryo itself, or are transmitted by the mother.

In birds, direct abiotic environmental factors (e.g., temperature) can influence embryonic development and the adult phenotype (see [106]). It has been shown that exposure of embryos to different temperatures at the end of egg incubation, which is a critical developmental period, can be a way of adapting poultry embryos to later climatic conditions (see [106]). Epigenetic processes are good candidates for mediating these mechanisms [107-110]. Another example of abiotic stress influencing embryonic development is the exposure to green monochromatic LED light during embryogenesis that has a growth-promoting effect observed on adult turkeys and broiler chickens [111-114]. One explanation may be enhanced proliferation and differentiation of adult myoblasts and myofiber synchronization [113], but further work is needed to better characterize the underlying processes.

The impact of the mother's environment on the F1 generation phenotype has been well documented in mammals. For example, it has been reported in humans, that the gestational diet affects offspring phenotypes (part of the "nutritional programming") (see [115]). A well-documented example comes from studies after the Dutch famine during World War II, which revealed that prenatal under-nutrition had an effect on later health [116] and that epigenetic mechanisms were involved [117]. The resulting chronic degenerative diseases associated with this famine include cardiovascular diseases, metabolic diseases, breast cancer and obesity. Another famous example of an adult phenotype induced by maternal nutrition in mammals is the viable yellow agouti $\left(\mathrm{A}^{\mathrm{vy}}\right)$ mouse model, in which the Agouti gene is genetically and epigenetically dysregulated by an upstream retrotransposon insertion. In this model, the diet of the mother influences coat color and other pleiotropic outcomes, such as diabetes, obesity and tumorigenesis in the offspring. Both methylation patterns and histone modifications are involved in the epigenetic variations of this mutation $[118,119]$.

Maternal under-nutrition can also affect the phenotype of offspring in birds. For example, Rao et al. showed that 4-week-old chicks from mothers fed a low-protein diet had significantly heavier body weight and Pectoralis major muscle weight [120]. Another approach consists in experimentally increasing brood size, which induces developmental deficits (including nutrient deficits) in the early life of birds. For example, in zebra finches, Naguib et al. [121,122] imposed different degrees of developmental stress on nestlings by forming broods ranging in size from two to six nestlings, and then examined the offspring of the dams that had been differentially stressed as nestlings. As the brood size experienced by the dams increased, the weight of their offspring decreased. The effects on body mass and size were sexspecific. Female offspring grew larger than male offspring when their dam was raised in a small brood, but females from dams reared in large broods were smaller than their brothers. Furthermore, the reproductive success of the female progeny was negatively associated with the brood size in which the dam was raised $[121,122]$. These maternal effects could result from modifications in egg content of the females that were stressed during their early development, leading to sexdependent impacts on the phenotype of F1 individuals. Epigenetic mechanisms might be involved in this process, and deserve to be examined in this context. Several studies have also proven the existence of a maternal influence on the immune system of $\mathrm{F} 1$ individuals in birds (see [123] for a review).

From a genetic point of view, it is interesting that the priming effect of these induced responses seems to depend on the maternal genetic background [124].

The most in-depth research on epigenetic effects in birds over a single generation focused on the effects of environmental challenges on behavioral traits, gene expression and DNA methylation in offspring [125-128]. In one of these studies [128], spatial learning was affected in individuals subjected to unpredictable light rhythms compared to animals exposed to predictable light rhythms. In the White Leghorn but not the Red Jungle Fowl, these effects were transmitted to the F1 generation reared under normal conditions, indicating a difference in the transmission of information to the next generation between these two chicken breeds. Exposure of commercial chicks to an unpredictable light schedule also triggered transmission of adaptive behavior to the next generation, with female offspring showing greater effects than males [127]. Molecular analyses showed that transcription differences acquired by the parents in response to environmental challenges are partially passed on to the F1 generation, and that the BDNF gene [128], immune genes [127], and stress-related genes [125] seem to be involved in these transmitted effects. This work also provides new insight into the role of DNA methylation in multigenerational epigenetic effects, by showing heritable differences of DNA methylation between different chicken breeds [126]. The influence of the genetic background is a particularly interesting feature and it has been reported that the impact of the parental 
environment on the offspring's phenotype depends on the chicken line [128]. Observations in quail have also demonstrated a genetic component of maternal influence. Cross-fostering of chicks by mothers from two quail lines, divergently selected for tonic immobility (a fear-related behavioral trait), showed that the level of maternal influence on the offspring's behavioral development depends on the chick's genetic origin [129]. This maternal influence is at least partially carried by egg composition, as shown in a study of F1 quails from stressed females [130] and using an ex-ovo embryo transfer strategy between chicken layers and broilers [104].

Collectively, the above-described examples yield two noteworthy conclusions. First, some of the early environmental effects on the offspring's phenotype are sex-specific in both birds and mammals. Second, the environment experienced during early development seems to have a greater impact on the adult phenotype than that experienced later in life (Figure 2).

Taken together, these examples show that the environment influences gene expression in avian species, perhaps via epigenetic mechanisms. An interesting feature in the context of poultry production and selection is the possibility that these influences may be retained across several successive generations.
Transgenerational memory of the ancestors' environment An example of transgenerational epigenetic transmission comes from the plant world. Johannes et al. showed that alterations in DNA methylation can be inherited for several generations in Arabidopsis thaliana [131]. Using epiRIL (epigenetic Recombinant Inbred Lines), these authors and others [132] examined the transmission of epigenetic marks for at least eight generations, and observed that some were conserved while others gradually returned to their original methylation state.

Similarly, interesting cases have been highlighted in animals. Erasure of methylation patterns during meiosis results in the establishment of new parent-specific imprints in oocytes and spermatocytes ([15,133], see Figure 2). However, some loci can escape DNA methylation reprogramming, as for example, repeated elements such as retrotransposons [15,134]. Moreover, miRNA were shown to be involved in the transmission of epigenetic information via the gametes $[15,135]$. Thus, epigenetic information can be transmitted and have an impact on the next generations.

Parental environment has an effect on the F1 generation and this is particularly clear in mammals, since the mother hosts the offspring's development from the zygote stage to birth. Such effects will also occur in the

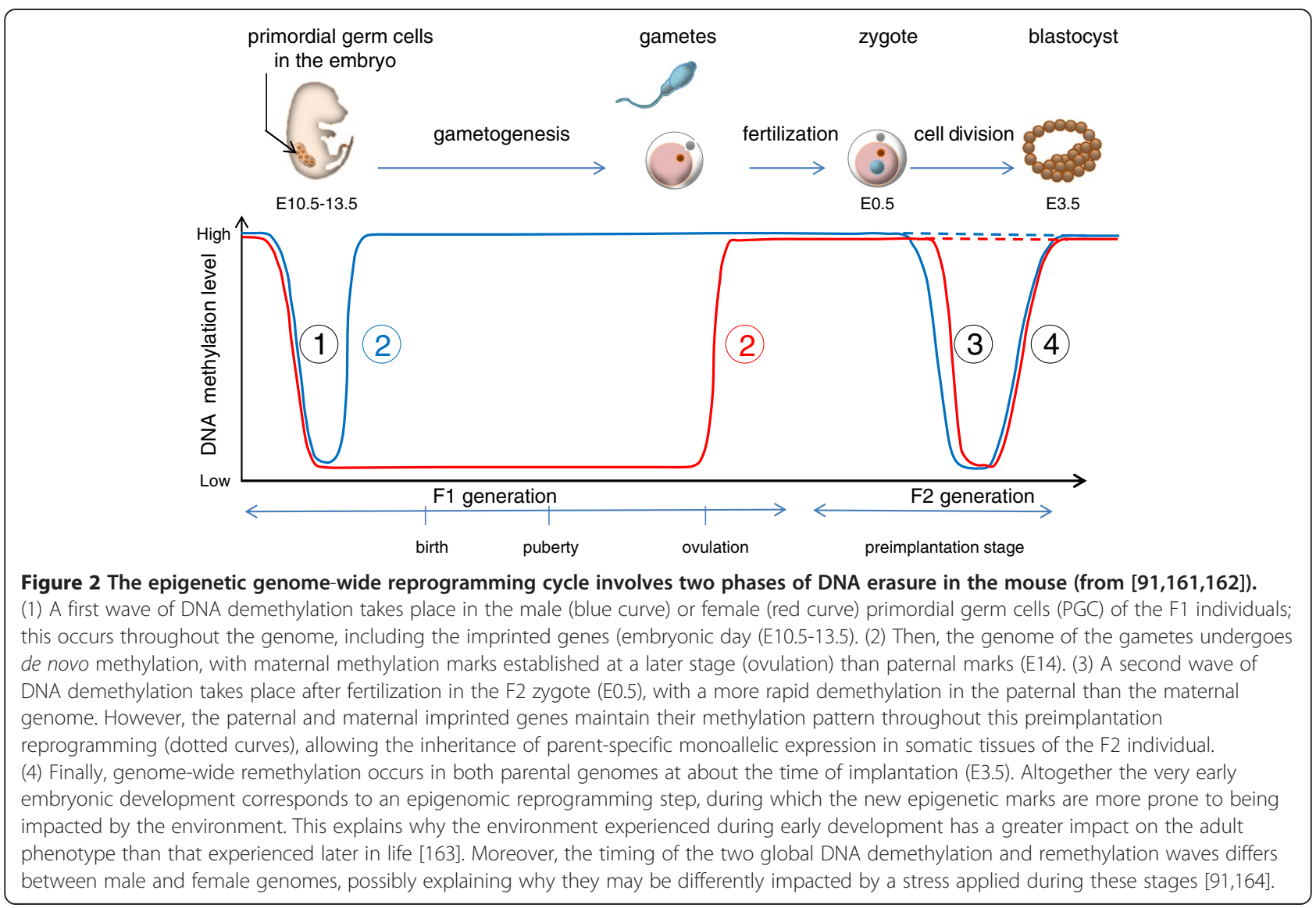


F2 generation, since the developing F1 generation bears the primordial germ cells that will differentiate into gamete precursor cells and eventually form an F2 animal. In this way, the maternal environment can affect the next two generations (Figure 3), which means that the first generation for which an individual's cells are not directly exposed to an environmental effect is the F3 generation if it was the female that was exposed and the F2 generation if it was the male. Thus, evidence for transgenerational epigenetic transmission, i.e. incomplete erasure of epigenetic marks between generations resulting in unusual patterns of inheritance from one generation to the next, is unquestionable only if the effect is detected in the F3 generation or beyond [136]. Investigating the malepath is an interesting approach to examine transgenerational epigenetic impacts.

Paternal environmental influences on the phenotype of the F1 generation (or even the F2 generation) have been shown in mammals (reviewed in [137]). For example, the female offspring of adult male rats fed a high-fat diet showed modified $\beta$-cell functions that were associated with an altered expression of more than 600 genes in the F1 generation, and hypomethylation of a cytosine proximal to the transcription start site of the IL13RA2 gene [138]. Similarly, offspring from male rats fed a low-

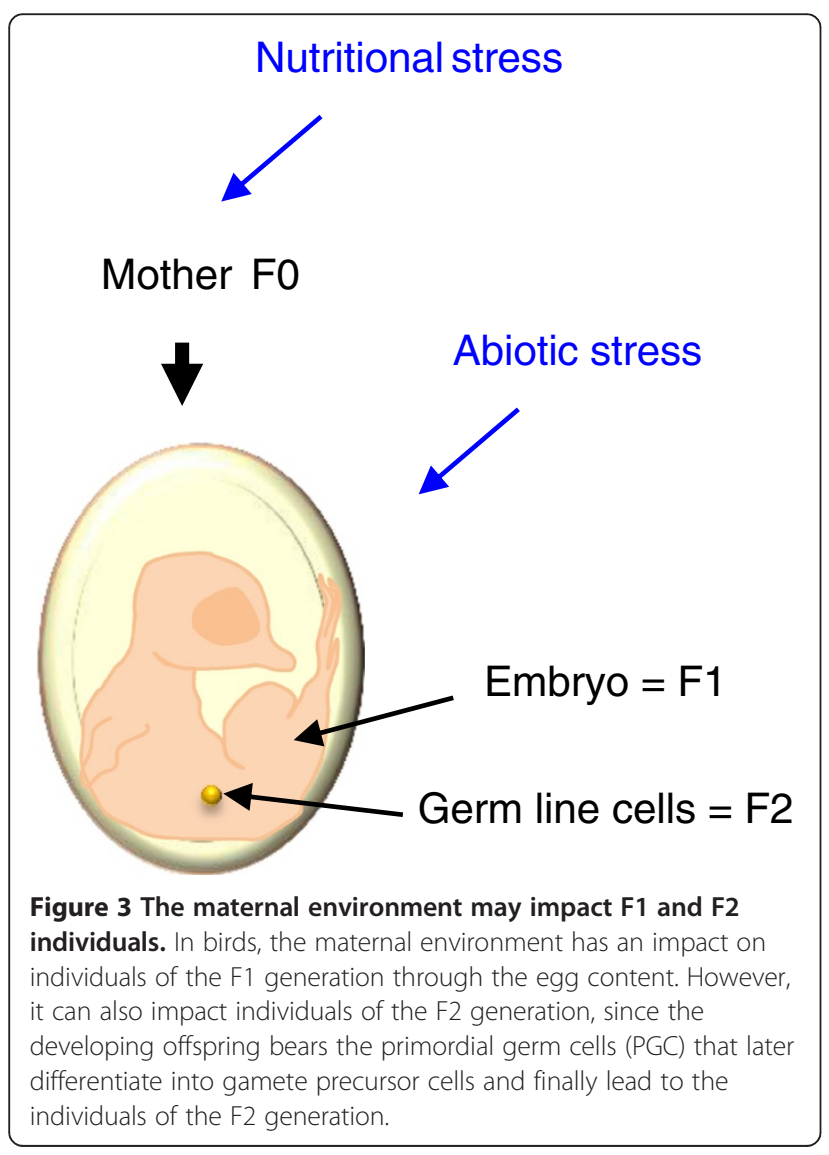

protein diet showed impaired lipid metabolism, notably associated with increased methylation at a putative enhancer of the PPAR $\alpha$ gene [139]. These results strongly suggest transmission of epigenetic information, but since the methylation patterns were not examined in the following generation, it is difficult to conclude to an unquestionable transgenerational epigenetic phenomenon, as defined above.

Transgenerational epigenetic transmission may be rare, but it has already been reported in different mammalian species. In man, Pembrey reported that the paternal grandfather's food supply affected the mortality rate of grandsons but not of granddaughters, whereas the paternal grandmother's food supply affected the mortality rate of granddaughters but not of grandsons [140,141]. Another study by Heijmans and collaborators showed that the risk of mortality in grandchildren, with respect to the grandparents' food supply, was associated with modifications of DNA methylation in the differentially methylated region of the IGF2 gene [117].

Recently, Zeybel et al. [142] described an adaptive mechanism involving epigenetic mechanisms in rats. After inducing liver injury in F0 and/or F1 males, they showed a reduction of liver fibrogenesis in F2 male offspring, illustrating an unquestionable transgenerational inheritance. The authors observed epigenetic modifications in a number of genes, with alterations observed in CpG methylation (PPAR,$P P A R \alpha$ and TGF- $\beta 1)$, histone $\mathrm{H} 3$ acetylation (PPAR $\gamma$ and TGF- $\beta 1)$ and other chromatin modifications $(P P A R \gamma)$. However, the mechanisms that transmit epigenetic modifications from the environment to the sperm and from the sperm to the offspring's liver have not yet been deciphered [142]. In rats, an epigenetic inheritance induced by different environmental components was observed in the sperm of the F3 generation by detecting differentially methylated regions depending on the environmental exposure of the ancestors [143].

Some studies have even revealed transmission of epigenetic marks to at least the F4 generation. Recently, Wolstenholme et al. reported that exposure to bisphenol A during the gestation of female mice reduced the expression of the genes encoding two neuropeptides (oxytocin and vasopressin) in the brain of the F1 individuals. The expression of oxytocin was still reduced in the brain of the F4 males and females, whereas decreased vasopressin expression was maintained only in the F4 males. Moreover, impacts on social behavior were detected until the F4 generation [144]. Another report on the analysis of the phenotype and epigenetic marks of female rats subjected to a high-energy diet for four generations, demonstrated that transgenerational effects involving altered epigenetic marks at each generation were induced (at least partly) de novo [145]. Finally, the best-studied 
example of transgenerational epigenetic inheritance in vertebrates concerns the influence of vinclozolin on the health (fertility problems or organic diseases) of rat male offspring in the F1 to F4 generations. This occurs via DNA methylation and a putative induction of copy number variation to generate new imprinted-like sites that are transmitted to subsequent generations through the male germ line, thus creating transgenerational transmission of adult phenotypes [146-149]. Other studies have suggested putative intergenerational transmission of epigenetic marks through the gametes $[15,135]$.

To our knowledge, no transgenerational transmission of epigenetic marks has been reported in birds, either prior to the exhaustive reviews by Jablonka and Raz [3] and Ho and Burggren [4], or since then.

\section{Conclusions}

A phenotype results from the interplay between the genome and the epigenome, which itself depends on the environment the animal experiences during its development and adult life. Epigenetic variations during early life play a role in producing inter-individual differences in phenotypes. Consequently, analyses of inter-individual phenotypic diversity should consider both epigenetic and genetic variations [93]. In this review, we describe epigenetic phenomena in birds in comparison to the related studies in mammals. Much more work is needed to fully comprehend the importance of epigenetics in the phenotypic variability of birds, and hence to exploit it for genetic selection.

In the chicken, epigenetic modifications occur from the first egg stage, i.e. a stage at which the dam provides an environmental signature through the egg content [150]. These environmental influences may have agronomic value via their effect on the adult phenotype. Given the likelihood that climate will change in the more or less near future and demands for food supplies will increase, a better understanding of the epigenetic mechanisms governing the embryo's response to environmental changes could open new ways to improve efficiency, animal welfare and food quality. For example, one interesting issue is the nutrient profile and restriction level of the diet of breeders, which is tailored to produce the largest possible number of fertile eggs and may thus not fill the requirements for future adult broiler performance [151].

Transgenerational inheritance associated with mechanisms other than DNA sequence variation (i.e., epigenetics, parental effects or "cultural inheritance") is thought to affect evolutionary dynamics [152]. This "non-classical" inheritance is known to play a role in phenotypic variability, especially in the response to environmental changes [153]. An important question in animal selection is the extent to which this non-genetic inheritance also affects the efficiency of genetic selection. Indeed, epigenetics may help to better explain environmental and non-Mendelian variability of complex traits [154]. Several authors have proposed quantitative models including epigenetic inheritance and environmental interactions [155-157], potentially paving the way for future inclusion of these mechanisms in genetic selection studies. The reversibility of epigenetic modifications (i.e., their potentially transient nature) could constitute a challenge in the modeling of inheritance [158]. Aside from putative epigenetic inheritance, Feinberg and coworkers proposed a model in which DNA mutations could, via epigenetic mechanisms, modify phenotypic variability without changing the mean phenotype [159]. This model should be considered by geneticists aiming at studying the adaptation of livestock to changing environments.

From a genetic point of view, the contribution of heritable epigenetic effects to important phenotypic variations is an exciting research area, not only for fundamental science, but also because of its possible breeding applications, as recently suggested by a primary poultry genetics organization [160].

\section{Competing interests}

The authors declare that they have no competing interests.

\section{Author's contributions}

LF, MM and FP drafted and finalized the manuscript. JMB, BP, AC and FM participated in bibliographic analyses and writing of the paper. All authors read and approved the final manuscript.

\section{Acknowledgements}

The authors thank Hervé Acloque for critical reading of the manuscript and Hélène Hayes for helpful comments. LF is supported by the Région Midi-Pyrénées and Animal Genetics Division (INRA). This work is supported by the French ANR EpiBird grant (ANR-009-GENM-004).

\section{Author details}

${ }^{1}$ INRA, UMR444, Laboratoire de Génétique Cellulaire, Castanet-Tolosan F-31326, France. ENVT, UMR444, Laboratoire de Génétique Cellulaire, Toulouse, F-31076, France. ${ }^{3}$ INRA, UR631, Station d'Amélioration Génétique des Animaux, Castanet-Tolosan, F-31326, France. ${ }^{4}$ INRA, UR83, Recherche Avicoles, Nouzilly F-37380, France. ${ }^{5}$ INSERM, U846, INRA, USC1361, Institut Cellule Souche et Cerveau, Bron F-69500, France. ${ }^{6}$ INRA, UMR1313, Génétique animale et biologie intégrative, Jouy-en-Josas F-78350, France.

${ }^{7}$ AgroParisTech UMR1313, Génétique animale et biologie intégrative, Jouy-en-Josas F-78350, France.

Received: 13 November 2012 Accepted: 26 April 2013

Published: 11 June 2013

\section{References}

1. Manolio TA, Collins FS, Cox NJ, Goldstein DB, Hindorff LA, Hunter DJ, McCarthy MI, Ramos EM, Cardon LR, Chakravarti A, Cho JH, Guttmacher AE, Kong A, Kruglyak L, Mardis E, Rotimi CN, Slatkin M, Valle D, Whittemore AS, Boehnke M, Clark AG, Eichler EE, Gibson G, Haines JL, Mackay TFC, McCarroll SA, Visscher PM: Finding the missing heritability of complex diseases. Nature 2009, 461:747-753.

2. Makowsky R, Pajewski NM, Klimentidis YC, Vazquez Al, Duarte CW: Allison $\mathrm{DB}$, de los Campos G: Beyond missing heritability: prediction of complex traits. PLoS Genet 2011, 7:e1002051.

3. Jablonka E, Raz G: Transgenerational epigenetic inheritance: prevalence, mechanisms, and implications for the study of heredity and evolution. Q Rev Biol 2009, 84:131-176.

4. Ho DH, Burggren WW: Epigenetics and transgenerational transfer: a physiological perspective. J Exp Biol 2010, 213:3-16. 
5. Holliday R: Epigenetics: a historical overview. Epigenetics 2006, 1:76-80.

6. Jablonka E, Lamb MJ: The changing concept of epigenetics. Ann N Y Acad Sci 2002, 981:82-96.

7. Bird A: Perceptions of epigenetics. Nature 2007, 447:396-398

8. Goldberg AD, Allis CD, Bernstein E: Epigenetics: a landscape takes shape. Cell 2007, 128:635-638.

9. Krause B, Sobrevia L, Casanello P: Epigenetics: new concepts of old phenomena in vascular physiology. Curr Vasc Pharmacol 2009, 7:513-520.

10. Ptashne M: On the use of the word 'epigenetic'. Curr Biol 2007, 17:R233-R236.

11. Ptashne M: Faddish stuff: epigenetics and the inheritance of acquired characteristics. FASEB J 2013, 27:1-2.

12. Youngson NA, Whitelaw E: Transgenerational epigenetic effects. Annu Rev Genomics Hum Genet 2008, 9:233-257.

13. Mazzio EA, Soliman KF: Basic concepts of epigenetics: impact of environmental signals on gene expression. Epigenetics 2012, 7:119-130

14. Feil R, Fraga MF: Epigenetics and the environment: emerging patterns and implications. Nat Rev Genet 2012, 13:97-109.

15. Daxinger $L$, Whitelaw $E$ : Understanding transgenerational epigenetic inheritance via the gametes in mammals. Nat Rev Genet 2012, 13:153-162.

16. Cockett NE, Jackson SP, Shay TL, Farnir F, Berghmans S, Snowder GD, Nielsen DM, Georges M: Polar overdominance at the ovine callipyge locus. Science 1996, 273:236-238.

17. Van Laere AS, Nguyen M, Braunschweig M, Nezer C, Collette C, Moreau L, Archibald AL, Haley CS, Buys N, Tally M, Andersson G, Georges M, Andersson L: A regulatory mutation in IGF2 causes a major QTL effect on muscle growth in the pig. Nature 2003, 425:832-836.

18. Park HB, Jacobsson L, Wahlberg P, Siegel PB, Andersson L: QTL analysis of body composition and metabolic traits in an intercross between chicken lines divergently selected for growth. Physiol Genomics 2006, 25:216-223.

19. Lyon MF: Gene action in the X-chromosome of the mouse (Mus musculus L.). Nature 1961, 190:372-373.

20. Morey C, Avner P: The demoiselle of X-inactivation: 50 years old and as trendy and mesmerising as ever. PLoS Genet 2011, 7:e1002212

21. Itoh Y, Replogle K, Kim YH, Wade J, Clayton DF, Arnold AP: Sex bias and dosage compensation in the zebra finch versus chicken genomes: general and specialized patterns among birds. Genome Res 2010, 20:512-518.

22. Ellegren H, Hultin-Rosenberg L, Brunström B, Dencker L, Kultima K, Scholz B: Faced with inequality: chicken do not have a general dosage compensation of sex-linked genes. BMC Biol 2007, 5:40.

23. Julien $P$, Brawand D, Soumillon M, Necsulea A, Liechti A, Schütz F, Daish T, Grützner $\mathrm{F}$, Kaessmann $\mathrm{H}$ : Mechanisms and evolutionary patterns of mammalian and avian dosage compensation. PLOS Biol 2012, 10:e1001328.

24. Teranishi M, Shimada Y, Hori T, Nakabayashi O, Kikuchi T, Macleod T, Pym R, Sheldon B, Solovei I, Macgregor H, Mizuno S: Transcripts of the MHM region on the chicken $Z$ chromosome accumulate as non-coding RNA in the nucleus of female cells adjacent to the DMRT1 locus. Chromosome Res 2001, 9:147-165.

25. Melamed E, Arnold AP: Regional differences in dosage compensation on the chicken Z chromosome. Genome Biol 2007, 8:R202.

26. Mank JE, Ellegren $\mathrm{H}$ : All dosage compensation is local: gene-by-gene regulation of sex-biased expression on the chicken $Z$ chromosome. Heredity 2009, 102:312-320

27. Zhang SO, Mathur S, Hattem G, Tassy O, Pourquié O: Sex-dimorphic gene expression and ineffective dosage compensation of Z-linked genes in gastrulating chicken embryos. BMC Genomics 2010, 11:13.

28. Livernois AM, Graves JA, Waters PD: The origin and evolution of vertebrate sex chromosomes and dosage compensation. Heredity 2012, 108:50-58.

29. Da Rocha ST, Ferguson-Smith AC: Genomic imprinting. Curr Biol 2004 14:R646-R649

30. Prickett AR, Oakey RJ: A survey of tissue-specific genomic imprinting in mammals. Mol Genet Genomics 2012, 287:621-630

31. Ideraabdullah FY, Vigneau S, Bartolomei MS: Genomic imprinting mechanisms in mammals. Mutat Res 2008, 647:77-85.

32. Moore T, Haig D: Genomic imprinting in mammalian development: a parental tug-of-war. Trends Genet 1991, 7:45-49.

33. Haig D, Graham C: Genomic imprinting and the strange case of the insulin-like growth factor II receptor. Cell 1991, 64:1045-1046.

34. Iwasa Y: The conflict theory of genomic imprinting: how much can be explained? Curr Top Dev Biol 1998, 40:255-293.
35. Fairfull RW: Heterosis. In Poultry Breeding and Genetics. Edited by Crawford RD. Amsterdam: Elsevier Science Publishers; 1990:913-933.

36. Tuiskula-Haavisto M, Vilkki J: Parent-of-origin specific QTL-a possibility towards understanding reciprocal effects in chicken and the origin of imprinting. Cytogenet Genome Res 2007, 117:305-312.

37. Rowe SJ, Pong-Wong R, Haley CS, Knott SA, De Koning DJ: Detecting parent of origin and dominant QTL in a two-generation commercial poultry pedigree using variance component methodology. Genet Sel Evol 2009, 41:6.

38. Sharman PWA, Morrice DR, Law AS, Burt DW, Hocking PM: Quantitative trait loci for bone traits segregating independently of those for growth in an F2 broiler X layer cross. Cytogenet Genome Res 2007, 117:296-304.

39. Tuiskula-Haavisto M, De Koning DJ, Honkatukia M, Schulman NF, Mäki-Tanila A, Vilkki J: Quantitative trait loci with parent-of-origin effects in chicken. Genet Res 2004, 84:57-66.

40. Navarro P, Visscher PM, Knott SA, Burt DW, Hocking PM, Haley CS: Mapping of quantitative trait loci affecting organ weights and blood variables in a broiler layer cross. Br Poult Sci 2005, 46:430-442.

41. Minvielle F, Kayang BB, Inoue-Murayama M, Miwa M, Vignal A, Gourichon D, Neau A, Monvoisin JL, Ito S: Microsatellite mapping of QTL affecting growth, feed consumption, egg production, tonic immobility and body temperature of Japanese quail. BMC Genomics 2005, 6:87.

42. Siwek M, Cornelissen SJB, Nieuwland MGB, Buitenhuis AJ, Bovenhuis $H$, Crooijmans RPMA, Groenen MAM, De Vries-Reilingh G, Parmentier HK, Van Der Poel JJ: Detection of QTL for immune response to sheep red blood cells in laying hens. Anim Genet 2003, 34:422-428.

43. Buitenhuis AJ, Rodenburg TB, Van Hierden YM, Siwek M, Cornelissen SJ, Nieuwland MG, Crooijmans RPMA, Groenen MAM, Koene P, Korte SM, Bovenhuis $\mathrm{H}$, Van der Poel JJ: Mapping quantitative trait loci affecting feather pecking behavior and stress response in laying hens. Poult $\mathrm{SCl}$ 2003, 82:1215-1222.

44. De Koning DJ, Bovenhuis H, Van Arendonk JAM: On the detection of imprinted quantitative trait loci in experimental crosses of outbred species. Genetics 2002, 161:931-938.

45. Sandor C, Georges M: On the detection of imprinted quantitative trait loci in line crosses: effect of linkage disequilibrium. Genetics 2008, 180:1167-1175.

46. Barlow DP, Stöger R, Herrmann BG, Saito K, Schweifer N: The mouse insulin-like growth factor type-2 receptor is imprinted and closely linked to the Tme locus. Nature 1991, 349:84-87.

47. Bartolomei MS, Zemel S, Tilghman SM: Parental imprinting of the mouse H19 gene. Nature 1991, 351:153-155.

48. DeChiara TM, Robertson EJ, Efstratiadis A: Parental imprinting of the mouse insulin-like growth factor II gene. Cell 1991, 64:849-859.

49. Gregg C, Zhang J, Weissbourd B, Luo S, Schroth GP, Haig D, Dulac C: Highresolution analysis of parent-of-origin allelic expression in the mouse brain. Science 2010, 329:643-648.

50. Kelsey G, Bartolomei MS: Imprinted genes... and the number is? PLOS Genet 2012, 8:e1002601.

51. DeVeale B, Van der Kooy D, Babak T: Critical Evaluation of Imprinted Gene Expression by RNA-Seq: A New Perspective. PLoS Genet 2012, 8:e1002600.

52. O'Neill MJ, Ingram RS, Vrana PB, Tilghman SM: Allelic expression of IGF2 in marsupials and birds. Dev Genes Evol 2000, 210:18-20.

53. Suzuki S, Shaw G, Kaneko-Ishino T, Ishino F, Renfree M: Characterisation of marsupial PHLDA2 reveals eutherian specific acquisition of imprinting. BMC Evol Biol 2011, 11:244.

54. Killian JK, Nolan CM, Stewart N, Munday BL, Andersen NA, Nicol S, Jirtle RL: Monotreme IGF2 expression and ancestral origin of genomic imprinting. J Exp Zool 2001, 291:205-212.

55. Renfree MB, Hore TA, Shaw G: Marshall Graves JA, Pask AJ: Evolution of genomic imprinting: insights from marsupials and monotremes. Annu Rev Genomics Hum Genet 2009, 10:241-262.

56. Giannoukakis N, Deal C, Paquette J, Goodyer CG, Polychronakos C: Parental genomic imprinting of the human IGF2 gene. Nat Genet 1993, 4:98-101.

57. Koski LB, Sasaki E, Roberts RD, Gibson J, Etches RJ: Monoalleleic transcription of the insulin-like growth factor-II gene (lgf2) in chick embryos. Mol Reprod Dev 2000, 56:345-352.

58. Nolan CM, Killian JK, Petitte JN, Jirtle RL: Imprint status of M6P/IGF2R and IGF2 in chickens. Dev Genes Evol 2001, 211:179-183.

59. Wang G, Yan B, Deng X, Li C, Hu X, Li N: Insulin-like growth factor 2 as a candidate gene influencing growth and carcass traits and its bialleleic expression in chicken. Sci China C Life Sci 2005, 48:187-194. 
60. Yokomine T, Kuroiwa A, Tanaka K, Tsudzuki M, Matsuda Y, Sasaki H: Sequence polymorphisms, allelic expression status and chromosome locations of the chicken IGF2 and MPR1 genes. Cytogenet Genome Res 2001, 93:109-113.

61. Yokomine T, Shirohzu H, Purbowasito W, Toyoda A, Iwama H, Ikeo K, Hori T, Mizuno S, Tsudzuki M, Matsuda Y, Hattori M, Sakaki Y, Sasaki H: Structural and functional analysis of a $0.5-\mathrm{Mb}$ chicken region orthologous to the imprinted mammalian Ascl2/Mash2-Igf2-H19 region. Genome Res 2005, 15:154-165.

62. Shin S, Han JY, Lee K: Cloning of avian Delta-like 1 homolog gene: The biallelic expression of Delta-like 1 homolog in avian species. Poult Sci 2010, 89:948-955

63. Colosi DC, Martin D, Moré K, Lalande M: Genomic organization and allelic expression of UBE3A in chicken. Gene 2006, 383:93-98.

64. Kitsberg D, Selig S, Brandeis M, Simon I, Keshet I, Driscoll DJ, Nicholls RD, Cedar $\mathrm{H}$ : Allele-specific replication timing of imprinted gene regions. Nature 1993, 364:459-463.

65. Dünzinger U, Nanda I, Schmid M, Haaf T, Zechner U: Chicken orthologues of mammalian imprinted genes are clustered on macrochromosomes and replicate asynchronously. Trends Genet 2005, 21:488-492.

66. Dünzinger $U$, Haaf $T$, Zechner U: Conserved synteny of mammalian imprinted genes in chicken, frog, and fish genomes. Cytogenet Genome Res 2007, 117:78-85.

67. Bartolomei MS, Ferguson-Smith AC: Mammalian genomic imprinting. Cold Spring Harbor Perspect Biol 2011, 3:a002592.

68. Jin B, Li Y, Robertson KD: DNA methylation: superior or subordinate in the epigenetic hierarchy? Genes Cancer 2011, 2:607-617.

69. Jurkowska RZ, Jurkowski TP, Jeltsch A: Structure and function of mammalian DNA methyltransferases. ChemBioChem 2011, 12:206-222.

70. Hata K, Okano M, Lei H, Li E: Dnmt3L cooperates with the Dnmt3 family of de novo DNA methyltransferases to establish maternal imprints in mice. Development 2002, 129:1983-1993.

71. Suetake I, Shinozaki F, Miyagawa J, Takeshima H, Tajima S: DNMT3L stimulates the DNA methylation activity of Dnmt3a and Dnmt3b through a direct interaction. J Biol Chem 2004, 279:27816-27823.

72. Jia D, Jurkowska RZ, Zhang X, Jeltsch A, Cheng X: Structure of Dnmt3a bound to Dnmt3L suggests a model for de novo DNA methylation. Nature 2007, 449:248-251.

73. Ooi SKT, Qiu C, Bernstein E, Li K, Jia D, Yang Z, Erdjument-Bromage $H_{\text {, }}$ Tempst P, Lin SP, Allis CD, Cheng X, Bestor TH: DNMT3L connects unmethylated lysine 4 of histone $\mathrm{H} 3$ to de novo methylation of DNA. Nature 2007, 448:714-717.

74. Van Emburgh BO, Robertson KD: Modulation of Dnmt3b function in vitro by interactions with Dnmt3L, Dnmt3a and Dnmt3b splice variants. Nucleic Acids Res 2011, 39:4984-5002.

75. Smallwood SA, Tomizawa S, Krueger F, Ruf N, Carli N, Segonds-Pichon A, Sato S, Hata K, Andrews SR, Kelsey G: Dynamic CpG island methylation landscape in oocytes and preimplantation embryos. Nat Genet 2011, 43:811-814

76. Weaver JR, Sarkisian G, Krapp C, Mager J, Mann MRW, Bartolomei MS: Domain-specific response of imprinted genes to reduced DNMT1. Mol Cell Biol 2010, 30:3916-3928.

77. Yokomine T, Hata K, Tsudzuki M, Sasaki H: Evolution of the vertebrate DNMT3 gene family: a possible link between existence of DNMT3L and genomic imprinting. Cytogenet Genome Res 2006, 113:75-80.

78. Tajima S, Tsuda H, Wakabayashi N, Asano A, Mizuno S, Nishimori K: Isolation and expression of a chicken DNA methyltransferase cDNA. J Biochem 1995, 117:1050-1057.

79. Bourc'his D, Proudhon C: Sexual dimorphism in parental imprint ontogeny and contribution to embryonic development. Mol Cell Endocrinol 2008, 282:87-94.

80. Li Q, Li N, Hu X, Li J, Du Z, Chen L, Yin G, Duan J, Zhang H, Zhao Y, Wang J, Li N: Genome-wide mapping of DNA methylation in chicken. PLoS One 2011, 6:e19428.

81. Delaval K, Govin J, Cerqueira F, Rousseaux S, Khochbin S, Feil R: Differential histone modifications mark mouse imprinting control regions during spermatogenesis. EMBO J 2007, 26:720-729

82. Kim JM, Ogura A: Changes in allele-specific association of histone modifications at the imprinting control regions during mouse preimplantation development. Genesis 2009, 47:611-616.

83. McEwen KR, Ferguson-Smith AC: Distinguishing epigenetic marks of developmental and imprinting regulation. Epigenetics Chromatin 2010, 3:2.
84. Sleutels F, Zwart R, Barlow DP: The non-coding Air RNA is required for silencing autosomal imprinted genes. Nature 2002, 415:810-813.

85. Lewis A, Mitsuya K, Umlauf D, Smith P, Dean W, Walter J, Higgins M, Feil R, Reik W: Imprinting on distal chromosome 7 in the placenta involves repressive histone methylation independent of DNA methylation. Nat Genet 2004, 36:1291-1295.

86. Peters J, Williamson CM: Control of imprinting at the Gnas cluster. Epigenetics 2007, 2:207-213.

87. Williamson CM, Ball ST, Dawson C, Mehta S, Beechey CV, Fray M, Teboul L, Dear TN, Kelsey G, Peters J: Uncoupling antisense-mediated silencing and DNA methylation in the imprinted Gnas cluster. PLoS Genet 2011, 7:e1001347.

88. Barbaux S, Gascoin-Lachambre G, Buffat C, Monnier P, Mondon F, Tonanny MB, Pinard A, Auer J, Bessières B, Barlier A, Jacques S, Simeoni U, Dandolo L, Letourneur $F$, Jammes $H$, Vaiman D: A genome-wide approach reveals novel imprinted genes expressed in the human placenta. Epigenetics 2012, 7:1079-1090.

89. Kelsey G: Epigenetics and the brain: transcriptome sequencing reveals new depths to genomic imprinting. BioEssays 2011, 33:362-367.

90. Cooper WN, Constância M: How genome-wide approaches can be used to unravel the remaining secrets of the imprintome. Brief Funct Genomics 2010, 9:315-328.

91. Faulk C, Dolinoy DC: Timing is everything: the when and how of environmentally induced changes in the epigenome of animals. Epigenetics 2011, 6:791-797.

92. Jammes $\mathrm{H}$, Junien $\mathrm{C}$, Chavatte-Palmer P: Epigenetic control of development and expression of quantitative traits. Reprod Fertil Develop 2010, 23:64-74.

93. Szyf M, McGowan P, Meaney MJ: The social environment and the epigenome. Environ Mol Mutagen 2008, 49:46-60.

94. Kisliouk T, Meiri N: A critical role for dynamic changes in histone $\mathrm{H} 3$ methylation at the Bdnf promoter during postnatal thermotolerance acquisition. Eur J Neurosci 2009, 30:1909-1922.

95. Kisliouk T, Ziv M, Meiri N: Epigenetic control of translation regulation: alterations in histone $\mathrm{H} 3$ lysine 9 post-translation modifications are correlated with the expression of the translation initiation factor $2 \mathrm{~B}$ (Eif2b5) during thermal control establishment. Dev Neurobiol 2010, 70:100-113.

96. Kisliouk T, Yosefi S, Meiri N: MiR-138 inhibits EZH2 methyltransferase expression and methylation of histone $\mathrm{H} 3$ at lysine 27 , and affects thermotolerance acquisition. Eur J Neurosci 2011, 33:224-235.

97. Yossifoff M, Kisliouk T, Meiri N: Dynamic changes in DNA methylation during thermal control establishment affect CREB binding to the brainderived neurotrophic factor promoter. Eur J Neurosci 2008, 28:2267-2277.

98. Gou Z, Liu R, Zhao G, Zheng M, Li P, Wang H, Zhu Y, Chen J, Wen J: Epigenetic modification of TLRs in leukocytes is associated with increased susceptibility to Salmonella enteritidis in chickens. PLoS One 2012, 7:e33627.

99. Luo J, Yu Y, Chang S, Tian F, Zhang H, Song J: DNA methylation fluctuation induced by virus infection differs between MD-resistant and susceptible chickens. Front Genet 2012, 3:20.

100. Luo J, Mitra A, Tian F, Chang S, Zhang H, Cui K, Yu Y, Zhao K, Song J: Histone methylation analysis and pathway predictions in chickens after MDV infection. PLoS One 2012, 7:e41849.

101. Yan F, Angel R, Ashwell C, Mitchell A, Christman M: Evaluation of the broiler's ability to adapt to an early moderate deficiency of phosphorus and calcium. Poult Sci 2005, 84:1232-1241.

102. Ashwell C, Angel R: Nutritional genomics: a practical approach by early life conditioning with dietary phosphorus. R Bras Zootec 2010, 39:268-278.

103. Xu P, Denbow CJ, Meiri N, Denbow DM: Fasting of 3-day-old chicks leads to changes in histone H3 methylation status. Physiol Behav 2012, 105:276-282.

104. Ho DH, Reed WL, Burggren WW: Egg yolk environment differentially influences physiological and morphological development of broiler and layer chicken embryos. J Exp Biol 2011, 214:619-628.

105. Reed WL, Clark ME: Beyond maternal effects in birds: responses of the embryo to the environment. Integr Comp Biol 2011, 51:73-80.

106. Renaudeau D, Collin A, Yahav S, De Basilio V, Gourdine JL, Collier RJ: Adaptation to hot climate and strategies to alleviate heat stress in livestock production. Animal 2011, 6:707-728.

107. Tzschentke B, Basta D: Early development of neuronal hypothalamic thermosensitivity in birds: influence of epigenetic temperature adaptation. Comp Biochem Physiol A Mol Integr Physiol 2002, 131:825-832. 
108. Shinder D, Ruzal M, Giloh M, Druyan S, Piestun Y, Yahav S: Improvement of cold resistance and performance of broilers by acute cold exposure during late embryogenesis. Poult Sci 2011, 90:633-641.

109. Nichelmann M, Höchel J, Tzschentke B: Biological rhythms in birdsdevelopment, insights and perspectives. Comp Biochem Physiol A Mol Integr Physiol 1999, 124:429-437.

110. Piestun Y, Shinder D, Ruzal M, Halevy O, Brake J, Yahav S: Thermal manipulations during broiler embryogenesis: effect on the acquisition of thermotolerance. Poult Sci 2008, 87:1516-1525.

111. Rozenboim I, Huisinga R, Halevy O, El Halawani ME: Effect of embryonic photostimulation on the posthatch growth of turkey poults. Poult Sci 2003, 82:1181-1187.

112. Rozenboim I, Piestun Y, Mobarkey N, Barak M, Hoyzman A, Halevy O: Monochromatic light stimuli during embryogenesis enhance embryo development and posthatch growth. Poult Sci 2004, 83:1413-1419.

113. Halevy O, Piestun Y, Rozenboim I, Yablonka-Reuveni Z: In ovo exposure to monochromatic green light promotes skeletal muscle cell proliferation and affects myofiber growth in posthatch chicks. Am J Physiol Regul Integr Comp Physiol 2006, 290:R1062-R1070.

114. Zhang L, Zhang HJ, Qiao X, Yue HY, Wu SG, Yao JH, Qi GH: Effect of monochromatic light stimuli during embryogenesis on muscular growth, chemical composition, and meat quality of breast muscle in male broilers. Poult Sci 2012, 91:1026-1031.

115. Gabory A, Attig L, Junien C: Epigenetic mechanisms involved in developmental nutritional programming. World J Diabetes 2011, 2:164-175.

116. Lumey LH, Stein AD, Kahn HS, Van der Pal-de Bruin KM, Blauw GJ, Zybert PA, Susser ES: Cohort profile: the Dutch Hunger Winter families study. Int J Epidemiol 2007, 36:1196-1204.

117. Heijmans BT, Tobi EW, Stein AD, Putter H, Blauw GJ, Susser ES, Slagboom PE, Lumey LH: Persistent epigenetic differences associated with prenatal exposure to famine in humans. Proc Natl Acad Sci USA 2008, 105:17046-17049.

118. Dolinoy DC: The agouti mouse model: an epigenetic biosensor for nutritional and environmental alterations on the fetal epigenome. Nutr Rev 2008, 66:S7-S11.

119. Dolinoy DC, Weinhouse C, Jones TR, Rozek LS, Jirtle RL: Variable histone modifications at the $\mathrm{A}(\mathrm{vy})$ metastable epiallele. Epigenetics 2010 5:637-644.

120. Rao K, Xie J, Yang X, Chen L, Grossmann R, Zhao R: Maternal low-protein diet programmes offspring growth in association with alterations in yolk leptin deposition and gene expression in yolk-sac membrane, hypothalamus and muscle of developing Langshan chicken embryos. BrJ Nutr 2009, 102:848-857.

121. Naguib M, Gil D: Transgenerational effects on body size caused by early developmental stress in zebra finches. Biol Lett 2005, 1:95-97.

122. Naguib M, Nemitz A, Gil D: Maternal developmental stress reduces reproductive success of female offspring in zebra finches. Proc Biol Sci 2006, 273:1901-1905.

123. Hasselquist D, Nilsson JA: Maternal transfer of antibodies in vertebrates: trans-generational effects on offspring immunity. Philos Trans $R$ Soc Lond B Biol Sci 2009, 364:51-60.

124. Navara KJ, Pinson SE: Yolk and albumen corticosterone concentrations in eggs laid by white versus brown caged laying hens. Poult Sci 2010, 89:1509-1513.

125. Goerlich VC, Nätt D, Elfwing M, Macdonald B, Jensen P: Transgenerational effects of early experience on behavioral, hormonal and gene expression responses to acute stress in the precocial chicken. Horm Behav 2012, 61:711-718.

126. Nätt D, Rubin CJ, Wright D, Johnsson M, Beltéky J, Andersson L, Jensen P: Heritable genome-wide variation of gene expression and promoter methylation between wild and domesticated chickens. BMC Genomics 2012, 13:59

127. Nätt $D$, Lindqvist $N$, Stranneheim $H$, Lundeberg J, Torjesen PA, Jensen P: Inheritance of acquired behaviour adaptations and brain gene expression in chickens. PLoS One 2009, 4:e6405.

128. Lindqvist $C$, Janczak AM, Nätt D, Baranowska I, Lindqvist N, Wichman A, Lundeberg J, Lindberg J, Torjesen PA, Jensen P: Transmission of stressinduced learning impairment and associated brain gene expression from parents to offspring in chickens. PLoS One 2007, 2:e364.

129. Houdelier C, Lumineau S, Bertin A, Guibert F, De Margerie E, Augery M, Richard-Yris MA: Development of fearfulness in birds: genetic factors modulate non-genetic maternal influences. PLoS One 2011, 6:e14604.
130. Guibert F, Richard-Yris MA, Lumineau S, Kotrschal K, Bertin A, Petton C, Möstl E, Houdelier C: Unpredictable mild stressors on laying females influence the composition of Japanese quail eggs and offspring's phenotype. Appl Anim Behav Sci 2011, 132:51-60.

131. Johannes F, Porcher E, Teixeira FK, Saliba-Colombani V, Simon M, Agier N, Bulski A, Albuisson J, Heredia F, Audigier P, Bouchez D, Dillmann C, Guerche $P$, Hospital F, Colot V: Assessing the impact of transgenerational epigenetic variation on complex traits. PLoS Genet 2009, 5:e1000530.

132. Reinders J, Wulff BB, Mirouze M, Mari-Ordonez A, Dapp M, Rozhon W, Bucher $E$, Theiler G, Paszkowski J: Compromised stability of DNA methylation and transposon immobilization in mosaic Arabidopsis epigenomes. Genes Dev 2009, 23:939-950.

133. Cedar H, Bergman Y: Programming of DNA methylation patterns. Annu Rev Biochem 2012, 81:97-117.

134. Law JA, Jacobsen SE: Establishing, maintaining and modifying DNA methylation patterns in plants and animals. Nat Rev Genet 2010, 11:204-220.

135. Marczylo EL, Amoako AA, Konje JC, Gant TW, Marczylo TH: Smoking induces differential miRNA expression in human spermatozoa: a potential transgenerational epigenetic concern? Epigenetics 2012, 7:432-439.

136. Skinner MK: Environmental epigenetic transgenerational inheritance and somatic epigenetic mitotic stability. Epigenetics 2011, 6:838-842.

137. Curley JP, Mashoodh R, Champagne FA: Epigenetics and the origins of paternal effects. Horm Behav 2011, 59:306-314.

138. Ng SF, Lin RCY, Laybutt DR, Barres R, Owens JA, Morris MJ: Chronic high-fat diet in fathers programs beta-cell dysfunction in female rat offspring. Nature 2010, 467:963-966.

139. Carone BR, Fauquier L, Habib N, Shea JM, Hart CE, Li R, Bock C, Li C, Gu H, Zamore PD, Meissner A, Weng Z, Hofmann HA, Friedman N, Rando OJ: Paternally induced transgenerational environmental reprogramming of metabolic gene expression in mammals. Cell 2010, 143:1084-1096.

140. Pembrey ME: Male-line transgenerational responses in humans. Hum Fertil 2010, 13:268-271.

141. Kaati G, Bygren LO, Pembrey M, Sjöström M: Transgenerational response to nutrition, early life circumstances and longevity. Eur J Hum Genet 2007, 15:784-790.

142. Zeybel M, Hardy T, Wong YK, Mathers JC, Fox CR, Gackowska A, Oakley F, Burt AD, Wilson CL, Anstee QM, Barter MJ, Masson S, Elsharkawy AM, Mann DA, Mann J: Multigenerational epigenetic adaptation of the hepatic wound-healing response. Nat Med 2012, 18:1369-1377.

143. Manikkam M, Guerrero-Bosagna C, Tracey R, Haque MM, Skinner MK Transgenerational actions of environmental compounds on reproductive disease and identification of epigenetic biomarkers of ancestral exposures. PLoS One 2012, 7:e31901.

144. Wolstenholme JT, Edwards M, Shetty SRJ, Gatewood JD, Taylor JA, Rissman EF, Connelly JJ: Gestational exposure to bisphenol A produces transgenerational changes in behaviors and gene expression. Endocrinology 2012, 153:3828-3838.

145. Burdge GC, Hoile SP, Uller T, Thomas NA, Gluckman PD, Hanson MA Lillycrop KA: Progressive, transgenerational changes in offspring phenotype and epigenotype following nutritional transition. PLOS One 2011, 6:e28282.

146. Anway MD, Cupp AS, Uzumcu M, Skinner MK: Epigenetic transgenerational actions of endocrine disruptors and male fertility. Science 2005, 308:1466-1469.

147. Chang HS, Anway MD, Rekow SS, Skinner MK: Transgenerational epigenetic imprinting of the male germline by endocrine disruptor exposure during gonadal sex determination. Endocrinology 2006, 147:5524-5541.

148. Guerrero-Bosagna C, Settles M, Lucker B, Skinner MK: Epigenetic transgenerational actions of vinclozolin on promoter regions of the sperm epigenome. PLoS One 2010, 5:e13100.

149. Skinner MK, Mohan M, Haque MM, Zhang B, Savenkova Ml: Epigenetic transgenerational inheritance of somatic transcriptomes and epigenetic control regions. Genome Biol 2012, 13:R91.

150. Monaghan P: Early growth conditions, phenotypic development and environmental change. Philos Trans R Soc Lond B Biol Sci 2008, 363:1635-1645.

151. Leeson S: Future considerations in poultry nutrition. Poult Sci 2012, 91:1281-1285 
152. Danchin E, Charmantier A, Champagne FA, Mesoudi A, Pujol B, Blanchet S: Beyond DNA: integrating inclusive inheritance into an extended theory of evolution. Nat Rev Genet 2011, 12:475-486.

153. Liu Y: Like father like son. A fresh review of the inheritance of acquired characteristics. EMBO Rep 2007, 8:798-803.

154. Petronis $A$ : Epigenetics as a unifying principle in the aetiology of complex traits and diseases. Nature 2010, 465:721-727.

155. Furrow RE, Christiansen FB, Feldman MW: Environment-sensitive epigenetics and the heritability of complex diseases. Genetics 2011, 189:1377-1387.

156. Johannes F, Colomé-Tatché M: Quantitative epigenetics through epigenomic perturbation of isogenic lines. Genetics 2011, 188:215-227.

157. Tal O, Kisdi E, Jablonka E: Epigenetic contribution to covariance between relatives. Genetics 2010, 184:1037-1050.

158. Slatkin M: Epigenetic inheritance and the missing heritability problem. Genetics 2009, 182:845-850.

159. Feinberg AP, Irizarry RA: Stochastic epigenetic variation as a driving force of development, evolutionary adaptation, and disease. Proc Natl Acad Sci USA 2009, 107:1757-1764

160. Fulton JE: Genomic selection for poultry breeding. Anim Front 2012, 2:30-36.

161. Jirtle RL, Skinner MK: Environmental epigenomics and disease susceptibility. Nat Rev Genet 2007, 8:253-262.

162. Feng S, Jacobsen SE, Reik W: Epigenetic reprogramming in plant and animal development. Science 2010, 330:622-627.

163. Heijmans BT, Tobi EW, Lumey LH, Slagboom PE: The epigenome: archive of the prenatal environment. Epigenetics 2009, 4:526-531.

164. Gabory A, Attig L, Junien C: Sexual dimorphism in environmental epigenetic programming. Mol Cell Endocrinol 2009, 304:8-18.

doi:10.1186/1297-9686-45-16

Cite this article as: Frésard et al:: Epigenetics and phenotypic variability: some interesting insights from birds. Genetics Selection Evolution 2013 45:16.

\section{Submit your next manuscript to BioMed Central and take full advantage of:}

- Convenient online submission

- Thorough peer review

- No space constraints or color figure charges

- Immediate publication on acceptance

- Inclusion in PubMed, CAS, Scopus and Google Scholar

- Research which is freely available for redistribution 